www.nature.com/jhg

\title{
Thalamic transcriptome screening in three psychiatric states
}

\author{
Tearina T Chu ${ }^{1}$, Yuexun Liu ${ }^{1}$ and Eileen Kemether ${ }^{2}$
}

The prefrontal cortex has been implicated in schizophrenia (SZ) and affective disorders by gene expression studies. Owing to reciprocal connectivity, the thalamic nuclei and their cortical fields act as functional units. Altered thalamic gene expression would be expected to occur in association with cortical dysfunction. We screened the expression of the entire human genome of neurons harvested by laser-capture microdissection (LCM) from the thalamic primary relay to dorsolateral prefrontal cortex in three psychiatric disease states as compared with controls. Microarray analysis of gene expression showed the largest number of dysregulated genes was in SZ, followed by major depression (MD) and bipolar mood bipolar (BP) (1152, 385 and 288, respectively). Significantly, IGF1-mTOR-, AKT-, RAS-, VEGF-, Wnt- and immune-related signaling, elF2- and proteasome-related genes were unique to SZ. Vitamin D receptor and calcium signaling pathway were unique to BP. AKAP95 pathway and pantothenate and CoA biosynthesis were unique to MD. There are significant differences among the three psychiatric disorders in MDNp cells. These findings offer new insights into the transcriptional dysregulation in the thalamus of SZ/BP/MD subjects. Journal of Human Genetics (2009) 54, 665-675; doi:10.1038/jhg.2009.93; published online 16 October 2009

Keywords: gene expression; LCM; mediodorsal nucleus; SZ; thalamus; transcriptome

\section{INTRODUCTION}

The thalamus, a subcortical brain region, is of interest in psychiatric disorders because its component nuclei provide links for multiple functional circuits that convey information to and from most regions of the cerebral cortex, including cortical regions implicated in schizophrenia (SZ) and affective disorders. ${ }^{1,2}$ As pathology in a particular brain region may induce both structural and functional abnormalities in its fields of projection, ${ }^{3}$ thalamic pathology might be expected to accompany disorders, including SZ, that involve cortical anomalies. Structural and functional abnormalities have previously been described in multiple cortical regions in SZ, in particular, the prefrontal cortex. ${ }^{4,5}$ Abnormalities in the thalamic regions with reciprocal prefrontal connections have been described in SZ by studies that used a variety of post-mortem and in vivo anatomical and functional techniques, ${ }^{6-9}$ although there have been some failures of replication. ${ }^{10-12}$ Thalamic subregions in living subjects with SZ have been shown to have decreased relative glucose utilization and blood oxygen level-dependent responses, suggesting that there is less relative neuronal activation in the mediodorsal nucleus (MDN) in SZ.,8,13-16 Dysregulation of glutamatergic neurotransmission has been thought to be involved in the molecular neuropathogenesis of SZ. ${ }^{17,18}$ Reduced glutamatergic activity in projections from the thalamus to dorsolateral prefrontal cortex (DLPFC) may, perhaps, affect the activity of cortical $\gamma$-aminobutyric acid (GABA) neurons in SZ. ${ }^{19}$

High-throughput gene expression studies offer another avenue for probing the thalamus for abnormalities related to psychiatric disorders. To date, relatively few studies have used rigorously quantitative methods to examine the thalamic gene expression in mental illness ${ }^{20}$ and none have used whole human genome screening. To screen the neuronal contribution to this circuit, we used microarray technology to screen full transcriptome expression of neurons accumulatively harvested from the parvocellular division of the MDN (MDNp) by laser-capture microdissection (LCM). We chose this thalamic subregion because of its extensive reciprocal connections with DLPFC, a cortical region responsible for working memory. The material for this study was provided by the Stanley Medical Research Institute (SMRI) and included equal numbers of specimens from subjects with SZ, bipolar mood disorder (BP), major depression (MD) and normal control (NC). Thus, it was possible not only to assess the abnormalities of thalamic MDNp gene expression in SZ, but also to determine whether those abnormalities were shared by other psychiatric disorders. In addition, it allowed us to see whether each disorder has a unique signature of gene expression abnormalities in the MDNp.

\section{MATERIALS AND METHODS}

Frozen post-mortem brain tissue was donated by the SMRI brain collection courtesy of Drs Michael B Knable, E Fuller Torrey, Maree J Webster, Serge Weis and Robert $\mathrm{H}$ Yolken, using approved protocols for tissue collection and informed consent. ${ }^{21}$ All brain specimens were screened by SMRI to exclude neuropathological abnormalities. The cohorts ( $n=15$ each, SZ/BP/MD/NC) were diagnosed according to DSM-IV criteria, and matched by age, sex, race,

${ }^{1}$ Department of Pharmacology and Systems Therapeutics, The Mount Sinai School of Medicine, New York City, NY, USA and ${ }^{2}$ Department of Psychiatry, The Mount Sinai School of Medicine, New York City, NY, USA

Correspondence: Dr E Kemether, Department of Psychiatry, Mount Sinai School of Medicine, 903 Park Avenue, Suite 2C, New York City, NY 10075-0361, USA

E-mail: eileen.kemether@mssm.edu

Received 9 January 2009; revised 21 July 2009; accepted 14 September 2009; published online 16 October 2009 
Table 1 Demographic information: diagnostic category (disease state, normal control), gender, case age, cumulative antipsychotic exposure, brain $\mathrm{pH}$ and post-mortem interval (PMI)

\begin{tabular}{|c|c|c|c|c|c|}
\hline Diagnosis & Gender & $\begin{array}{c}\text { Age at } \\
\text { death (years) }\end{array}$ & $\begin{array}{c}\text { Antipsychotics } \\
\text { (mg; lifetime) }\end{array}$ & $p H$ & PMI \\
\hline Schizophrenia & Female & 30 & 6000 & 6.2 & 60 \\
\hline Schizophrenia & Male & 52 & 9000 & 6 & 61 \\
\hline Schizophrenia & Female & 60 & 0 & 6.2 & 40 \\
\hline Schizophrenia & Male & 32 & 15000 & 6.1 & 19 \\
\hline Schizophrenia & Male & 60 & 80000 & 6.2 & 31 \\
\hline Schizophrenia & Female & 62 & 50000 & 6.1 & 26 \\
\hline Schizophrenia & Female & 49 & 200000 & 6.2 & 38 \\
\hline Schizophrenia & Male & 44 & 1000 & 6.5 & 50 \\
\hline Schizophrenia & Male & 35 & 50000 & 6.5 & 35 \\
\hline Schizophrenia & Male & 25 & 4000 & 6.6 & 32 \\
\hline Schizophrenia & Male & 25 & 4000 & 6.6 & 32 \\
\hline Bipolar & Female & 25 & 7500 & 6.4 & 24 \\
\hline Bipolar & Female & 37 & 1200 & 6.5 & 29 \\
\hline Bipolar & Male & 31 & 30000 & 6.3 & 28 \\
\hline Bipolar & Female & 61 & 40000 & 6.5 & 60 \\
\hline Bipolar & Male & 48 & 200 & 6.1 & 13 \\
\hline Bipolar & Male & 57 & 60000 & 6.2 & 19 \\
\hline Bipolar & Male & 30 & 0 & 6.3 & 45 \\
\hline Bipolar & Female & 50 & 12000 & 6.1 & 18 \\
\hline Bipolar & Male & 30 & 60000 & 6.1 & 31 \\
\hline Bipolar & Female & 50 & 0 & 6.3 & 62 \\
\hline Depression & Female & 44 & & 6.2 & 32 \\
\hline Depression & Male & 65 & & 6.2 & 19 \\
\hline Depression & Female & 30 & & 6 & 33 \\
\hline Depression & Female & 42 & & 6.3 & 25 \\
\hline Depression & Female & 53 & & 6.3 & 40 \\
\hline Depression & Male & 52 & & 6.5 & 12 \\
\hline Depression & Male & 39 & & 6 & 23 \\
\hline Depression & Male & 56 & & 6.5 & 23 \\
\hline Depression & Male & 47 & & 6.4 & 28 \\
\hline Depression & Male & 51 & & 6.3 & 26 \\
\hline Control & Male & 58 & & 6 & 27 \\
\hline Control & Female & 68 & & 6.3 & 13 \\
\hline Control & Female & 44 & & 6.3 & 25 \\
\hline Control & Male & 52 & & 6.5 & 8 \\
\hline Control & Male & 53 & & 6.2 & 28 \\
\hline Control & Female & 29 & & 6.2 & 42 \\
\hline Control & Male & 52 & & 6.2 & 22 \\
\hline Control & Male & 44 & & 6.4 & 10 \\
\hline Control & Male & 59 & & 6.4 & 26 \\
\hline Control & Male & 52 & & 6.5 & 28 \\
\hline Control & Female & 35 & & 6.6 & 23 \\
\hline Control & Male & 42 & & 6.6 & 27 \\
\hline
\end{tabular}

post-mortem interval (PMI), $\mathrm{pH}$ and side of the brain affected (Table 1). Coded specimens were provided to ensure that all studies were blinded. Samples were processed in random order throughout the course of study in order to minimize any systematic bias arising from sample preparation. The blind was retained until the full data set was received by SMRI.

\section{Template and tissue preparation for LCM}

A representative slide through the MDNp at the level of the dissections was selected for each subject, fixed with alcohol, stained with thionin and coverslipped (Figure 1). A sheet of clear acetate was then placed over the slide and the boundaries of the MDNp were traced onto it by one of the investigators

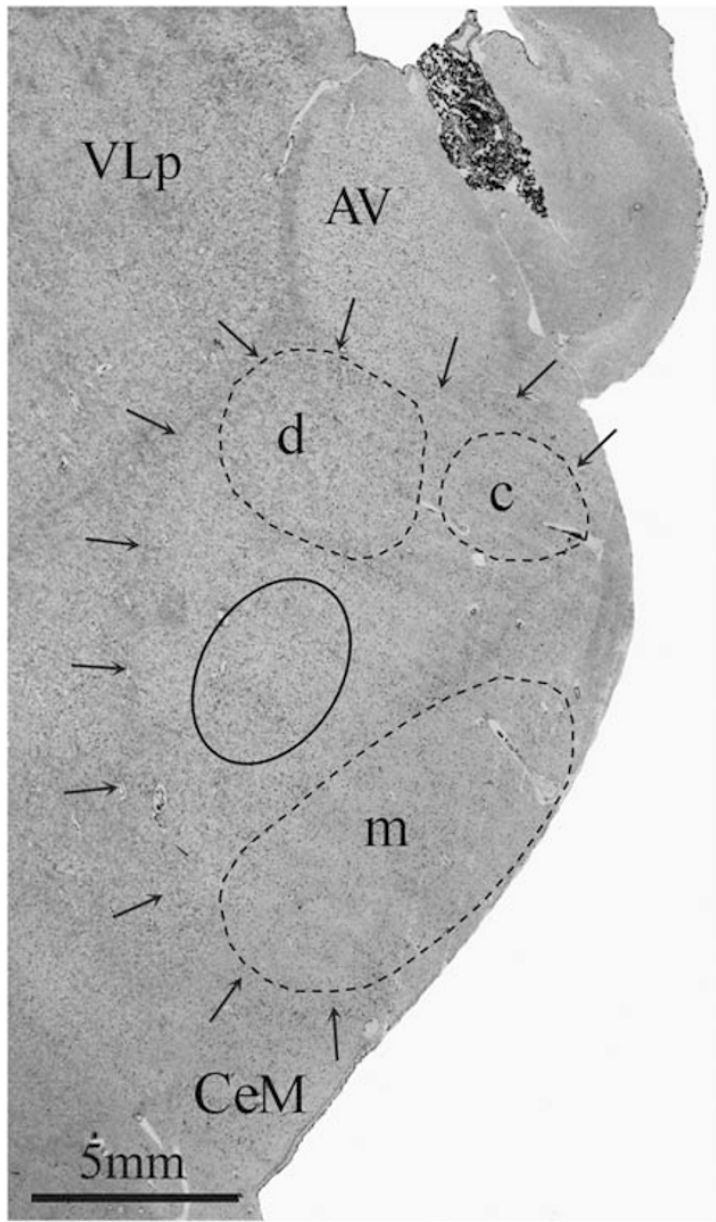

Figure 1 Coronal thionin stained $14-\mu \mathrm{m}$ thick cryostat section illustrating the region from which cells were harvested from the parvocellular region of the mediodorsal nucleus (MDNp; oval indicated by solid line). All dissections were made from sections at the rostrocaudal level at which the anterior ventral (AV), but not the anterior medial portion of the anterior principal nucleus was present. The MDNp was conceptualized as that part of the MDN that does not belong to its magnocellular (m), caudal (c) or densocellular (d) divisions. A region within the lateral portion of the MDNp was delineated for neuronal harvesting that was separated from the other divisions by a wide margin. The MDNm is situated ventromedially in the MDN and the MDNp is situated laterally. Dissection of the MDNp was restricted to the dorsolateral portion of the MDN to ensure that the harvest was enriched for cells of MDNp as opposed to MDNm. Although the divisions of the MDN are difficult to delineate precisely, compared with its medial region, the lateral region of the MDN projects to more lateral portions of prefrontal cortex. Thus, the neuronal preparations would be enriched for neurons that project to the lateral prefrontal cortex. Arrows demarcate the borders of the internal medullary lamina surrounding the mediodorsal nucleus. Abbreviations: AV, anterior ventral division of anterior principal nucleus; c, caudal division of MDN; CeM, central medial nucleus; d, densocellular division of MDN; $m$, magnocellular division of MDN; VLp, ventral lateral posterior nucleus.

(EK and reviewed by William Byne) with a fine-point marking pen while being viewed with a binocular dissecting microscope with zoom magnification ranging from $\times 6.3$ to 40 . The acetate template was then available to be placed underneath the adjacent uncoverslipped slides and aligned with the outer contours of the histological section to accurately delineate the region from which neurons were to be harvested using LCM. Colored sharpie markers were used to delineate the MDNp on the undersurface of the glass slide after fixation. Our subparcellation of the MDN follows that of Popken et al., ${ }^{9}$ with 
the exception that a region located at the caudomedial and dorsal edges of the MDN was not included with our parvocellular division. This division has been referred to as the pars dorsocaudalis and the pars caudalis by others. ${ }^{20,22}$

Using Rnase-free methods, tissue sections were quickly stained with thionin (for Nissl substance; Sigma-Aldrich, St Louis, MO, USA) as previously described $^{23}$ immediately before use. Tissue sections ( $14-\mu \mathrm{m}$ thick) placed on glass slides were submersed in cold $70 \%$ ethanol for $1 \mathrm{~min}$, rehydrated for $30 \mathrm{~s}$ in $\mathrm{ddH}_{2} \mathrm{O}$, stained with thionin (prepared under Rnase-free conditions) for $30 \mathrm{~s}$, rehydrated for $30 \mathrm{~s}$ and then treated further with successively graded ethanols $(70-100 \%)$ for $30 \mathrm{~s}$ each, dipped in xylene for $30 \mathrm{~s}$ and air dried for $5 \mathrm{~min}$. Graded ethanols and waters were chilled on an ice stage in order to maximize messenger RNA (mRNA) preservation. The Arcturus PixCell II laser capture microscope system (Mountain View, CA, USA) was used using the following settings: power $40-50 \mathrm{~mW}$, target $0.300 \mathrm{~V}$, temperature $22.4^{\circ} \mathrm{C}$, current 4.6 millihertz $(\mathrm{mH})$, repeat-laser pulse time $0.2 \mathrm{~s}$, duration 650 $700 \mu$ s, spot size $7.5 \mu \mathrm{m}$. Approximately 4000 neurons, the largest thioninstained cells, with the nucleus and cytoplasm visible, from consecutive sections were individually captured and pooled separately for each subject. LCM has been successfully used in human tissue, ${ }^{24}$ for the purposes of the identification of transcriptional changes in thalamic neural circuits ${ }^{25}$ and to profile thalamic subregion gene expression in primates. ${ }^{26}$

\section{RNA isolation, target preparation and microarray hybridization}

Total RNAs were isolated using RNeasy Micro Kit (Qiagen, Hilden, Germany) following the manufacturer's instruction. Purified RNA (1 ng) was subjected to quality evaluation by the Agilent BioAnalyzer pico RNA assay (Agilent Technologies, Palo Alto, CA, USA). We visually examined the electropherograms of all RNA samples, and those which showed two peaks of $18 \mathrm{~S}$ and $28 \mathrm{~S}$ ribosomal RNA (rRNA) were retained and subjected to amplification and GeneChip assay (Affymetrix, Santa Clara, CA, USA) regardless of the degree of degradation. Qualified RNAs were processed immediately to avoid damage to this small quantity of RNA during storage. Two cycles of linear amplification of the poly (A)-tailed RNA portion was required to yield a suitable quantity of antisense RNA (aRNA) for GeneChip gene expression profiling. The major length of the products from the second round of RNA amplification ranged between 1000 and 1500 nucleotides assayed by the BioAnalyzer. In all, $10 \mathrm{ng}$ of qualified total RNA was reverse transcribed using T7-poly(dT) primer and further converted into double-stranded cDNA using a Two-cycle cDNA synthesis kit (Affymetrix). The cDNA was then used as a template for an in vitro transcription reaction at $37^{\circ} \mathrm{C}$ for $16 \mathrm{~h}$ (Megascript kit, Ambion, Austin, TX, USA). The resulting amplified aRNA was column purified (Sample cleanup module, Affymetrix). The quantity and purity of the aRNA after the first cycle was determined by the Nano spectrophotometer ND-1000 (NanoDrop, Wilmington, DE, USA). A total of $300 \mathrm{ng}$ of aRNA were used as the template for the second cycle of amplification. The aRNA was first primed with random heximer for reverse transcription. T7-poly(dT) primer was then used for the second-strand cDNA synthesis to yield a double-stranded cDNA template for subsequent in vitro transcription with biotin-labeled UTP at $37^{\circ} \mathrm{C}$ for $16 \mathrm{~h}$ to yield biotin-labeled aRNA for hybridization (IVT labeling kit, Affymetrix). The aRNA was purified using the RNeasy minikit (Qiagen) and quality controlled by electrophoresis gel image and a spectrophotometric reading. In all, $15 \mu \mathrm{g}$ of the labeled aRNA were chemically fragmented and made into a hybridization cocktail, which was then hybridized to Human Genome U133 Plus 2.0 Arrays (Affymetrix), comprised of over 47000 transcripts and variants covering 38500 of the best-characterized human genes, according to the Affymetrix GeneChip protocol. The array images were generated through a high-resolution GeneChip Scanner 3000 7G (Affymetrix). Spike-in controls and percentage of present call generated based on MAS 5.0 within the GeneChip Operating Software were used for data quality control.

\section{Microarray data mining and analyses}

The samples were divided into nonpsychiatric control vs each disease (SZ vs NC; BP vs NC; MD vs NC) statistical groups for the disease candidate gene list. From the initial 60 ( $n=15$, each group), a total of 49 GeneChip data were generated initially. To identify potential data outliers, 49 arrays were normalized together at probe level using GeneChip Robust multi-array algorithms, ${ }^{27}$ followed by normalization to the median of all arrays, and then presented by a box plot covering the center 50 percentage of the data and distribution of data points $>3$ s.d. away from the median from each array across 49 samples (Supplementary Figure 1). Four subjects showing the most different global data distribution (that is, 45, 29, 39 and 55) were removed from the data set. Interestingly, all four outlier subjects had brain $\mathrm{pH}$ of $<6.0$. As brain $\mathrm{pH}$ has been suggested to have the most profound effects on post-mortem brain mRNA expression levels compared with other variables, including PMI, tissue storage time, gender, age, ${ }^{28,29}$ our analysis centered on a total of 43 subjects (11 from SZ, 10 from BP, 10 from MD and 12 from NC) following additional removal of 2 subjects with $\mathrm{pH}<6.0$. In addition, Welch's test (unpaired, unequal variance) was performed against four factors: (i) $\mathrm{pH}$ ( $\mathrm{pH} 6.0-6.2$ vs $\mathrm{pH}$ 6.3-6.6), (ii) gender (female vs male), (iii) PMI (8-26h vs $27-61 \mathrm{~h}$ ), as well as (iv) state (diseased vs normal) across 43 subjects, separately. Four gene lists were generated following the selection cutoffs at uncorrected $P$-value $<0.005$ and fold change $(\mathrm{FC}) \geqslant 1.5$, among which gender- and PMI-specific gene lists were used for later target corrections. Gender and PMI genes are shown in Supplementary Tables 1 and 2, respectively. Generic $\mathrm{pH}$ list was also shown in Supplementary Table 3; however, the disease-specific $\mathrm{pH}$ effect was corrected by two-way analysis of variance (ANOVA) as described later in the text. The effect of $\mathrm{pH}$, gender and PMI are shown in Supplementary Figure 2.

To identify genes whose expression level differed significantly from NCs, a similar normalization process was applied, except that the analysis was carried out within each disease compared with the control group. After normalization, genes were first filtered with signal criteria for inclusion of at least three arrays with $\geqslant 16$ signal intensity across both NC and SZ disease cohort arrays. Similar normalization and filtering procedures were applied to the BP and MD cohorts separately. This cutoff criterion removed $\sim 60 \%$ of probes with the least detection reliability in each disease group from further consideration. The intensity of each probe was log base 2 transformed. Average ratio for each gene (disease/control) was calculated and used for fold-change selection. Two-way ANOVA on disease and $\mathrm{pH}$ was carried out for each gene without multipletesting corrections for each disease vs control group. Genes with a $P$-value $<0.005$ and average $\mathrm{FC} \geqslant 1.5$ were selected for each disease group (as compared with NC) using GeneSpring (Agilent). These dysregulated gene lists, with their Affymetrix ID numbers imported into EASE (Expression Analysis Systematic Explorer) in DAVID (Database for Annotation, Visualization and Integrated Discovery), were used to identify functionally significant gene classes (http://david.niaid.nih.gov/david/ease.htm). ${ }^{30-32}$ This software uses statistical methods to map and identify functional gene categories (for example, Gene Ontology (GO), Kyoto Encyclopedia of Genes and Genomes (KEGG) or BioCarta), which are enriched in the significant gene list compared with their presence on the array.

\section{Real-time PCR}

A total of 33 genes showing differential expression between $\mathrm{SZ}$ and NC subjects, at one of the criteria: low $P$-value, high FC or of interest regardless of expression level, were selected for quantitative PCR (qPCR) confirmation (Table 2).

In all, $10 \mathrm{ng}$ of total RNA (the same as used on the arrays) were reverse transcribed and amplified using Ovation PCR amplification kit (NuGen, San Carlos, CA, USA), of which $2 \mathrm{ng}$ of amplified cDNA were used in each real-time PCR assay. All assays were carried out in triplicate using SyBR-Green on ABI 7900HT real-time PCR machine (Applied Biosystems, Foster City, CA, USA). The primer pair sequences were designed using Primer 3 software (http:// frodo.wi.mit.edu/) and tested for efficiency, accuracy and specificity by polyacrylamide gel electrophoresis before real-time PCR assay. Target cycle threshold $\left(\mathrm{C}_{\mathrm{t}}\right)$ number was normalized based on three reference genes, ribosomal protein S11 (RPS11), chromosome 9 open reading frame 6 (C9orf6) and chromosome 1 open reading frame 122 (C1orf122). Briefly, we first determined the median $\mathrm{C}_{\mathrm{t}}$ value of the triplicates for each RPS11, C9orf6 and C1orf122 among all subjects. The RPS11 or Clorf122 measurement for each subject was corrected by adding the difference $C_{t}$ between median $C_{t}$ of RPS11 (or C1orf122) and C9orf6. The median $C_{t}$ of the three reference genes was used as the final reference $C_{t}$ for each subject. The reference genes were checked for no differences between samples and association with disease state. The data analysis for establishing each target delta $C_{t}\left(\Delta C_{t}\right)$ was performed in MicroSoft 
Table 2 Quantitative PCR (qPCR) validation of altered gene expression in schizophrenia (see Real-time PCR section for further detail)

\begin{tabular}{|c|c|c|c|c|c|c|}
\hline \multirow[b]{2}{*}{ Affymetrix ID } & \multirow[b]{2}{*}{ Gene ID } & \multirow[b]{2}{*}{ Gene symbol } & \multicolumn{2}{|c|}{$q P C R$} & \multicolumn{2}{|c|}{ Microarray } \\
\hline & & & P-value & Fold change & $\mathrm{P}$-value & Fold change \\
\hline 208761_s_at & 7341 & SUMO1 & 0.037 & -1.5 & 0.001489 & -2.262643 \\
\hline 204313_s_at & 1385 & CREB1 & 0.004 & -4.7 & 0.002875 & -2.560745 \\
\hline 229905_at & 5910 & RAP1GDS1 & 0.014 & -3.8 & 0.001517 & -2.802889 \\
\hline 202843_at & 4189 & $D N A J B 9^{a}$ & 0.049 & -8.8 & $2.16 \mathrm{E}-04$ & -2.314427 \\
\hline 201237_at & 830 & $C A P Z A 2^{\mathrm{a}}$ & 0.0037 & -4.6 & 3.17E-04 & -4.039558 \\
\hline 208810_at & 10049 & $D N A J B 6^{a}$ & 0.007 & -3.6 & $3.68 \mathrm{E}-04$ & -2.154015 \\
\hline 201652_at & 10987 & COPS5 & 0.007 & -1.9 & 0.001046 & -2.271493 \\
\hline 200640_at & 7534 & YWHAZ & 0.014 & -2.7 & 0.004565 & -1.694877 \\
\hline 211936_at & 3309 & HSPA5 & 0.049 & -1.9 & 0.002637 & -1.84433 \\
\hline 212185_x_at & 4502 & MT2A & 0.007 & 3.1 & 0.001545 & 2.681438 \\
\hline 223605_at & 83733 & SLC25A18 & 0.003 & 4.4 & 0.004867 & 3.84271 \\
\hline 201020_at & 7533 & YWHAH & 0.037 & -4.6 & 0.002762 & -4.117142 \\
\hline 222484_s_at & 9547 & CXCL14 & 0.0018 & 5.72 & 0.006718 & 4.326997 \\
\hline 225990_at & 91653 & $B O C$ & 0.029 & 3.48 & 0.001033 & 3.679843 \\
\hline 221795_at & 4915 & NTRK2 & 0.049 & 5 & 0.004281 & 5.031255 \\
\hline 225532_at & 91768 & CABLES1 & 0.033 & 2.8 & 0.002057 & 2.992044 \\
\hline 200853_at & 3015 & $H 2 A F Z$ & $0.06^{*}$ & -1.38 & 0.003674 & -1.982723 \\
\hline 201972_at & 523 & ATP6V1A & 0.0008 & -1.92 & 0.002535 & -1.52367 \\
\hline 229159_at & 221981 & THSD7A & 0.0029 & -2.5 & 7.37E-04 & -2.204605 \\
\hline 232629_at & 60675 & PROK2 & 0.04 & -2.1 & 0.00224 & -2.262989 \\
\hline 215707_s_at & 5621 & PRNPa & 0.0024 & -2.38 & 4.48E-04 & -4.222806 \\
\hline
\end{tabular}

aDenotes those from list after $\mathrm{pH}$ correction.

The asterisk denotes not significant or approaching significance.

Excel, determining mean $\mathrm{SZ} \Delta \mathrm{C}_{\mathrm{t}}-\mathrm{NC} \Delta \mathrm{C}_{\mathrm{t}}\left(\Delta \Delta \mathrm{C}_{\mathrm{t}}\right)$ and significance testing for each target gene. A Mann-Whitney test was used to determine the significance of the qPCR data using a commercial add-on statistics module in Excel (Analyse-it Software, Leeds, UK).

Owing to the limited quantity of total RNA isolated from the LCM neurons, it was necessary to amplify the poly-A RNA before performing either the microarray or real-time PCR assays. As the end products of amplification for microarray assay and qPCR are aRNA and antisense DNA, respectively, we used different mRNA amplification methods for microarray and qPCR assays (T7-based amplification for microarray and Nugen SPIA amplification for qPCR). However, both were linear mRNA amplification methods.

\section{RESULTS}

Despite disease/control categories, 4 low brain $\mathrm{pH}$ outliers were identified when data from all 49 subjects were examined as a single data set in a box plot where the middle 50\% (range 25th to 75th percentile) of signal intensity of all transcripts was plotted for each array. With the removal of an additional two low $\mathrm{pH}$ subjects, the remaining samples showed a comparable intensity distribution pattern after a global normalization (data not shown). In each analysis of disease vs NC, out of 54675 probes on the arrays, 22 720, 22424 and 22347 probes (for SZ, BP and MD, respectively) passed the minimum signal intensity across 24,23 and 23 samples SZ/BP/MD, respectively). This indicates that $\sim 40 \%$ of the genome was expressed or detectable in these MDNp neuron preparations. Further analyses included genes that were of low-expression signal intensity (at least 3 of 24) in order to include low-abundance genes and to identify potential diseasespecific suppression of gene expression. Among the retained probes, 21836 (data not shown), the vast majority did not exhibit significant differences in the expression between any two disease groups, suggesting a similar gene expression pattern regardless of disease state.

Of the 43 samples, there were 4 variances, which we tested using Welch's test. The resulting significant gene list for each variance and their interrelationship were presented by a four-way Venn diagram (see Supplementary Figure 2). As expected, the primary variance in our data set was disease state (2304), followed by $\mathrm{pH}$ (375), gender (34) and PMI (25). In subsequent disease-specific statistical analyses, as $\mathrm{pH}$ had the most significant impact, to reduce complexity, we carried out a two-way ANOVA (on disease and $\mathrm{pH}$ ) that rendered three gene lists (SZ vs NC), (MD vs NC) and (BP vs NC). From these lists, we removed PMI- and gender-related genes.

Owing to the large number of dysregulated genes detected, to reduce the false-positive rate, we applied an arbitrary cutoff minimum bidirectional FC of 1.5 in addition to the $P$-value significance cutoff. Even though this cutoff may increase type II errors (false negatives), especially those with sensitive regulation control, many dysregulated genes were detected. Regardless of the FC cutoff, more genes were 


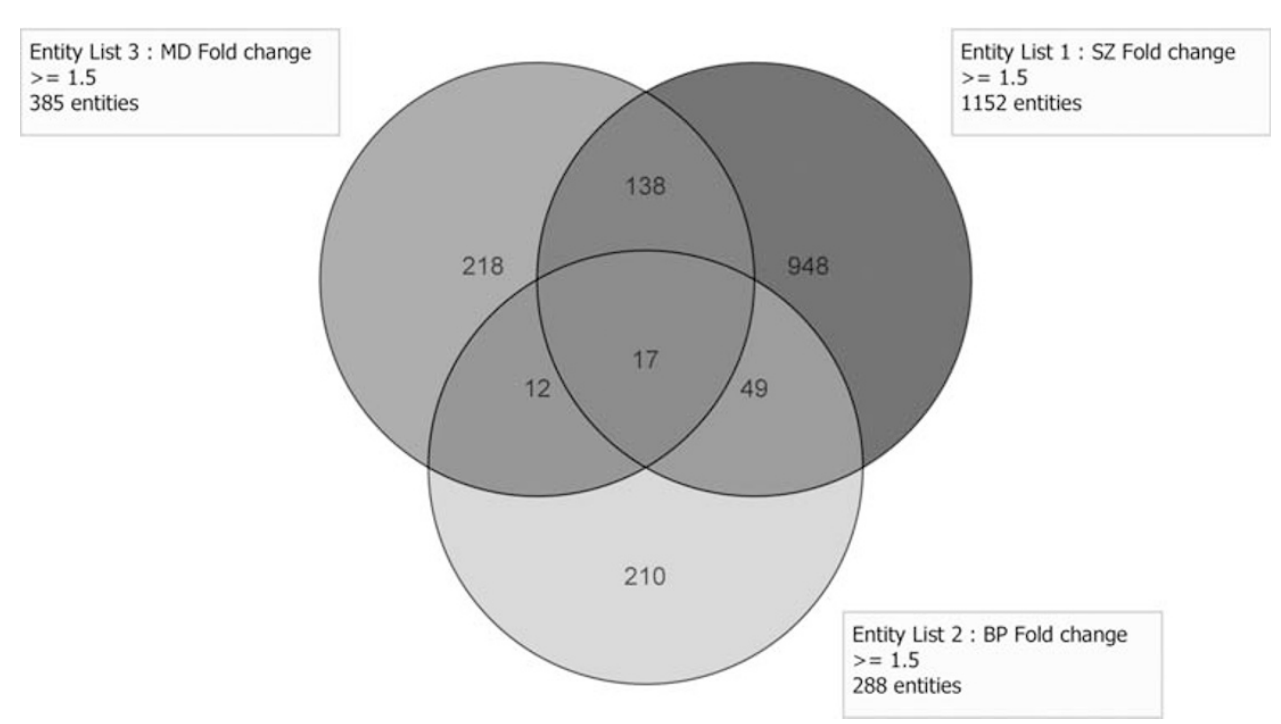

Figure 2 Venn diagram of three disease states, major depression (MD) (upper left; red), schizophrenia (SZ) (upper right; blue) and bipolar mood disorder (BP) (bottom center; green). Although 17 dysregulated genes were common to all disease states, many were unique to each disease state (948, 218 and 210 for SZ, MD and BP, respectively). (see Results section for further details). A full color version of this figure is available at the Journal of Human Genetics journal online.

found to be dysregulated in SZ compared with the other diagnostic groups. A large percentage of the dysregulated genes in each of the psychiatric cohorts were downregulated. We examined the possibility that global intensity may skew toward NC samples after normalization; however, no directional bias was suggested by intensity scatter plots of each disease state vs NC (data not shown).

The largest number of dysregulated transcripts was in the SZ group (1152), followed by MD (385) and BP (288) as compared with NC. Although 17 dysregulated genes were common to all disease states, many were unique to each disease state $(948,218$ and 210 for SZ, MD and $\mathrm{BP}$, respectively) (Figure 2.). Despite variation in the number and specific gene identified in the three disease states, many of the Gene Ontology biological process groupings were the same in two disease states (data not shown).

Many of the genes that were decreased in each disease cohort clustered within common functional classes by both the EASE algorithm wrapped in the DAVID web analyzer. Functional clusters of genes within BioCarta or KEGG pathways that were dysregulated in each disorder are summarized in Tables 3 and 4a. Only the BioCarta rabPathway was common to both SZ and MD (Table 3a), whereas ubiquitin-mediated proteolysis of KEGG was common to SZ/BP/MD (see Table $4 \mathrm{~b}$ ).

There were 168, 51 and 86 significant GO terms for SZ/BP/MD, respectively (Supplementary Tables 4-6). Among those, 21 biological processes were common in all three diseases, which involved various functions, including post-translational protein modification and Golgi vesicle transport (Supplementary Table 7).

A PubMed search of SZ association and linkage studies after the year 2000 identified 88 genes as being susceptible. In surveying our gene lists for each disease state for these 88 genes, 6,1 and 1 genes $(P<0.005, \mathrm{FC} \geqslant 1.5)$ showed transcriptional changes in SZ/BP/MD, respectively. The following genes were dysregulated in: (i) SZ: CHGB, GCLC, GLS, PANK2, PPP3CC, SLC25A12; (ii) BP: TOM1; and (iii) MD: PANK2.

Thirty-three differentially expressed genes in SZ were selected for PCR validation. This selection covers 33 genes in the categories of either showing the lowest $P$-value, the highest FC or of interest regardless of the expression level in both directions of regulation. Both microarray and qPCR data are summarized in Table 2. Although we purposely selected genes in the most favorable ends for confirmation, this gene pool includes genes with FC ranging from 1.5 to 5 (median=2.1), and $P$-value from 0.0048 to 0.000045 (median= 0.0015 ) at a preset arbitrary cutoff of 1.5 and 0.005 , respectively. We found all genes tested by qPCR showed consistent direction of regulation as that of the microarray data, among which 29 were confirmed $(P<0.05)$ with 2 additional ones being unspecific at a close cutoff. This result suggests that we are able to reach $\sim 88 \%$ confirmation rate of selective microarray genes by $\mathrm{qPCR}$. Although the selection of genes for $\mathrm{qPCR}$ validation to prove the principle of this microarray screening analysis was initiated before the $\mathrm{pH}$ correction, nine genes are retained after the correction (Table 2) and are indicated by the superscript letter 'a'. Nonetheless, the remaining 21 genes are confirmed according to the disease $P$-value regardless of $\mathrm{pH}$ correction. Although we preferentially chose genes of higher significance and a high confirmation rate, we assume that we have generated, overall, a reasonable significant gene list for each disease state.

The 28/22/3 transcripts were upregulated (Supplementary Tables 8 , 10 and 12) and 1120/261/378 transcripts were downregulated in the SZ/BP/MD cohorts, respectively. All downregulated transcripts listed in Supplementary Tables 9, 11 and 13 were above FC of 2.0.

\section{DISCUSSION}

This study surveyed the entire transcriptome of neurons from a thalamic division in post-mortem tissue from NCs and three psychiatric disorders. The largest number of transcriptional changes was detected in the SZ cohort, with the majority downregulated. These findings suggest that the genetic expression of MDNp neurons is more severely altered in SZ than in BP or MD. This is not surprising as the MDNp was chosen because it and its cortical target, DLPFC, have been implicated in SZ. We will focus the discussion on various qPCRvalidated genes for SZ (Table 2) and some of the top functional pathways dysregulated (Tables 3 and $4 \mathrm{a}$ ).

In surveying our list of genes dysregulated in SZ against various canonical biologic networks and pathways in an effort to elucidate the 
Table 3 Enriched BioCarta terms for three diseases

\begin{tabular}{|c|c|c|}
\hline Schizophrenia vs NC & P-value & Genes \\
\hline h_eif2Pathway:Regulation of elF2 & $1.89 \mathrm{E}-04$ & $\begin{array}{l}\text { 201143_s_at,208706_s_at, 209971_x_at,202138_x_at, } \\
\text { 224935_at, 226183_at, 225164_s_at, }\end{array}$ \\
\hline h_aktPathway:AKT Signaling Pathway & 0.019818 & $\begin{array}{l}\text { 235980_at, 235502_at, 210211_s_at, 212688_at, } \\
\text { 205451_at, }\end{array}$ \\
\hline $\begin{array}{l}\text { h_cdc42racPathway:Role of PI3K subunit p85 in regulation of Actin Organization } \\
\text { and Cell Migration }\end{array}$ & 0.012066 & 235980_at, 1567458_s_at, 214230_at, 224813_at, \\
\hline h_salmonellaPathway:How does salmonella hijack a cell & 0.046277 & 1567458_s_at, 214230_at, 224813_at, \\
\hline \multicolumn{3}{|l|}{ Bipolar vs NC } \\
\hline h_vdrPathway:Control of Gene Expression by Vitamin D Receptor & 0.005161 & 209105_at, 225456_at, 208794_s_at, 228177_at, \\
\hline h_p53hypoxiaPathway:Hypoxia and p53 in the Cardiovascular system & 0.052899 & $\begin{array}{l}\text { 243338_at, 211968_s_at, 211969_at, 209798_at, } \\
\text { 213579_s_at, }\end{array}$ \\
\hline h_akap95Pathway:AKAP95 role in mitosis and chromosome dynamics & 0.036361 & 235502_at, 225886_at, 228729_at, \\
\hline h_telPathway:Telomeres, Telomerase, Cellular Aging, and Immortality & 0.03371 & $\begin{array}{l}\text { 203449_s_at, 235502_at, 211968_s_at, 211969_at, } \\
\text { 214352_s_at,204009_s_at, }\end{array}$ \\
\hline \multicolumn{3}{|l|}{ BioCarta term common to SZ (first) and MDE (below) } \\
\hline h_rabPathway:Rab GTPases Mark Targets In The Endocytotic Machinery (SZ vs NC) & 0.004363 & $\begin{array}{l}\text { 201048_x_at, 208731_at, 200864_s_at, 213440_at, } \\
\text { 208724_s_at, 211960_s_at, }\end{array}$ \\
\hline h_rabPathway:Rab GTPases Mark Targets In The Endocytotic Machinery (MD vs NC) & 0.08232 & 201048_x_at, 209089_at, 208724_s_at, \\
\hline
\end{tabular}

Abbreviations: MD, major depression; NC, normal control; SZ, schizophrenia.

Affymetrix ID numbers of significant differentially expressed gene list for each disease were imported into Expression Analysis Systematic Explorer in Database for Annotation, Visualization and Integrated Discovery to identify functionally significant gene classes.

functional significance of the dysregulated genes, twelve functional pathways were specific to the SZ cohort. IGF1-mTOR- RAS-, AKT-, Wnt-, VEGF- and B-cell receptor signaling pathways implicate dysregulation of insulin signaling and the possibility of ongoing immuneand development-related changes. The finding of glutamate metabolism (approaching significance) may also provide support for dysregulation of transcripts involved in the availability and/or synthesis of glutamate for reuptake and neurotransmission in at least a subset of the glutamatergic thalamocortical neurons of the MDNp in SZ. Glutamate is released presynaptically and taken up by astrocytes and returned to the neuron as glutamine to make glutamate. Only glutaminase mRNA (neuronal), which converts glutamine to glutamate in neurons, not glutamine synthetase (astrocytic), was downregulated in our MDNp SZ cohort. However, decreased glutamine synthetase in the superior temporal gyrus and anterior cingulate cortex in SZ was recently reported. ${ }^{33}$ Over 100 insulin-responsive genes have previously been reported to be altered in SZ hippocampal neurons in a direction opposing their response to insulin, and the study of these various genes in relation to IGF1 in human neuroblastoma cells have been implicated in SZ. ${ }^{34,35}$ These studies also show that pharmacological stimulation of muscarinic and insulin/IGF1 receptors reverse the gene expression changes in specific subsets of genes that have been dysregulated in SZ, further highlighting the importance of insulin signaling. ${ }^{34}$ Our finding of gene-expression changes involved in the IGF1-mTOR signaling pathways is the first report, to our knowledge, in human SZ post-mortem tissues. Further consideration of the potential influence of medication on these findings or whether they are disease-related is necessary. Our present findings of IGF1-mTOR-, AKT- and Wnt-signaling dysregulation in MDNp neurons in SZ lend further support to both Akt-GSK3 $\beta$-Wnt signaling and insulin signaling deficits previously reported in SZ. ${ }^{36,37}$ As dysregulation of glucose utilization has been shown in living subjects with SZ and decreased numbers of insulin receptors in SZ post-mortem brain have been reported, ${ }^{4,8,13,16,36}$ dysregulation of this pathway may be involved in the molecular neuropathology of hypofunctional thalamocortical neurons in this circuit. Moreover, mTOR signaling also has a role in enhancing mitochondrial oxidative phosphorylation. ${ }^{38}$

Of our MDNp qPCR-validated genes (Table 2), YWHAH and YWHAZ, have been previously shown to be differentially expressed in the temporal lobe in SZ. ${ }^{39}$ Of the qPCR-validated genes on the $\mathrm{pH}$ corrected analysis (Table 2 marked with the superscript letter ' $a$ '), DNAJB6 (DnaJ (Hsp40) homolog, subfamily B, member 6 (also known as heat shock protein J2), RAD1 (RAD1 homolog (Schizosaccharomyses pombe) (aka checkpoint control protein HRAD1) and NRXN3 (neurexin 3) will be discussed with regard to SZ.

DnaJB6, also known as mammalian relative of DnaJ (Mrj), has been shown to inhibit NFAT transcriptional activity through recruitment of histone deacetylase after heat shock stimulation. ${ }^{40} \mathrm{RAD} 1$ is part of a 9-1-1 complex (Ras9-Hus1-Rad1), which, in concert with chromatin, 
Table 3a Gene names from Table 3 BioCarta terms for each category



may have a role in the response of neurons to various DNA damage. ${ }^{41}$ Neurexins are neuronal-specific cell surface proteins, which stabilize synapses, provide receptors for neuroligins, $\alpha$-latrotoxins, neuroexophilins, dystroglycans and are cell adhesion molecules at excitatory and inhibitory synapses. ${ }^{42-47}$ Neurexins prompt postsynaptic differentiation and induce neurotransmitter receptor clustering. . $^{4,48}$ NRXN3 polymorphisms have been linked with alcohol dependence, and NRXN3 has also been associated with nicotine and opiate dependence, the wide diversity of variants, brain regions and circuits are underreported at present. ${ }^{49-51} \mathrm{NRXN} 3$ has not been reported in SZ to date to our knowledge. Thus, the role of NRXN3 in synaptogenesis and its interaction with neuroligins in specific neuronal circuits may potentially increase the risk for SZ.

Various dysregulated dentate granule neuronal genes in $\mathrm{SZ}^{35}$ are listed for comparison with our MDNp findings (Supplementary
Table 14). However, when samples with $\mathrm{pH}<6.0$ were removed from the cohort, and high $(\geqslant \mathrm{pH} 6.3)$ and low $(\leqslant \mathrm{pH} 6.2)$ were analyzed, mRNA expression of energy metabolism markers were no longer found to be significant in our cohort. ${ }^{52-55}$ As $\mathrm{pH}$ has been shown to be an influential factor in post-mortem gene expression, ${ }^{54-56}$ on removal of subjects with extremely low $\mathrm{pH}$, our data also showed that energyand mitochondria-related genes were $\mathrm{pH}$ related.

With the likelihood of multiple genes, each having a small odds ratio (for example, single-nucleotide polymorphisms) common variances in multiple genes with small effect may manifest in a phenotype-environment interaction leading to disease susceptibility. Genetic variation leads to change of gene function, which ultimately leads to differences in translational functioning, which may have phenotypic contribution to disease state. Various genes implicated in SZ by linkage and association studies were found in each of the three 
cohorts. This suggests that genetic-linked disease associated genes may have a downstream transcriptional effect in one (disease-specific) or multiple (nonspecific) disease states. Although altered mRNA expression may not be the sole mechanism by which genetic variation confers disease susceptibility, ${ }^{57}$ our data suggest that the change of function of these genes may directly contribute to disease neuropathology.

Meta-analysis of linkage and positional cloning studies along with genome-wide association analysis point to predisposition to SZ through multiple genes of moderate to small effect. ${ }^{58-60}$ The likelihood of genes of major effect being responsible for SZ has largely been rejected. ${ }^{61}$ Rather, many genes conferring increased susceptibility is thought more realistically the case. ${ }^{62}$ Conceptually, various susceptibility genes, in non-static combination(s), along with epigenetic components, may be acting early in development to set in motion a cascade of genetic interactions resulting in disease. From a few genes, the expression of many genes ultimately contributes to extensive dysregulation of synapses, neurotransmitters and signal transduction pathways in specific cells and regional neural circuits responsible for the multiple symptoms and behaviors associated with SZ. This MDNp transcriptome screening provides multiple genes, likely each of small effect, for consideration of the underlying molecular mechanisms involved in the neuropathogenesis of SZ. Thus, both previously

Table 4a Enriched KEGG terms for three diseases

\begin{tabular}{|c|c|c|}
\hline KEGG term & P-value & Genes AFFY ID \\
\hline \multicolumn{3}{|l|}{ Schizophrenia vs NC } \\
\hline hsa05110:Cholera - Infection & 0.0564 & 208898_at, 201097_s_at, 2646_s_at, 204732_s_at, 226463_at, 202872_at, 238765_at, \\
\hline $\begin{array}{l}\text { hsa04662:B cell receptor signaling } \\
\text { pathway }\end{array}$ & 0.047003 & 235980_at, 204507_s_at, 229606_at, 1567458_s_at, 212688_at, 32541_at, 226183_at, 228388_at, \\
\hline hsa04370:VEGF signaling pathway & 0.027504 & $\begin{array}{l}\text { 235980_at, 204507_s_at, 242323_at, 229606_at, 202670_at, 567458_s_at, 212688_at, 32541_at, } \\
\text { 214230_at, }\end{array}$ \\
\hline hsa03050:Proteasome & 0.023708 & 201233_at, 237240_at, 200876_s_at, 200830_at,201316_at, 201317_s_at, \\
\hline hsa00251:Glutamate metabolism & 0.064728 & 203157_s_at, 200843_s_at, 229333_at, 202922_at, 209434_s_at, \\
\hline hsa04310:Wnt signaling pathway & 0.021564 & $\begin{array}{l}\text { 204507_s_at, 32541_at, 13849_s_at, 201381_x_at, 235502_at, 229606_at, 212072_s_at, 201614_s_at, } \\
\text { 226666_at, 1567458_s_at, 219683_at, 226183_at, 209455_at, 235780_at, 202762_at, }\end{array}$ \\
\hline \multicolumn{3}{|l|}{ Bipolar vs NC } \\
\hline hsa04020:Calcium signaling pathway & 0.047107 & $\begin{array}{l}\text { 204507_s_at, 209281_s_at, 206355_at, 206356_s_at, 236013_at, 238546_at, 241752_at, 235049_at, } \\
\text { 207522_s_at, }\end{array}$ \\
\hline \multicolumn{3}{|l|}{ Major depression vs NC } \\
\hline $\begin{array}{l}\text { hsa00770:Pantothenate and } \mathrm{CoA} \\
\text { biosynthesis }\end{array}$ & 8.73E-04 & 218341_at,202993_at, 225285_at, 218809_at, 218433_at, \\
\hline hsa04730:Long-term depression & 0.061262 & 205630_at, 203710_at, 235502_at, 213849_s_at, 214352_s_at, 204009_s_at, 227692_at, \\
\hline hsa04110:Cell cycle & 0.042664 & $\begin{array}{l}\text { 222036_s_at, 204853_at, 214848_at, 209903_s_at, 213699_s_at, 212426_s_at, 213579_s_at, } \\
\text { 202892_at, 228729_at, }\end{array}$ \\
\hline $\begin{array}{l}\text { hsa00563:Glycosylphosphatidylinosi- } \\
\text { tol(GPI)-anchor biosynthesis }\end{array}$ & 0.0206 & 205077_s_at, 205078_at, 1552291_at, 241801_at, 223470_at, \\
\hline hsa04530:Tight junction & 0.01222 & $\begin{array}{l}\text { 202085_at, 235502_at, 225198_at, 221660_at, 213306_at, 214230_at, 210844_x_at, 213849_s_at, } \\
\text { 214352_s_at, 204009_s_at, 227692_at, }\end{array}$ \\
\hline
\end{tabular}

Abbreviations: KEGG, Kyoto Encyclopedia of Genes and Genomes; NC, normal control.

Affymetrix ID numbers of significant differentially expressed gene list for each disease were imported into Expression Analysis Systematic Explorer in Database for Annotation, Visualization and Integrated Discovery) to identify functionally significant gene classes.

Table 4b KEGG term common to three psychiatric disease states

\begin{tabular}{|c|c|c|}
\hline & P-value & Genes AFFY ID \\
\hline \multicolumn{3}{|l|}{ Schizophrenia } \\
\hline $\begin{array}{l}\text { hsa04120:Ubiquitin mediated } \\
\text { proteolysis }\end{array}$ & $3.14 \mathrm{E}-04$ & $\begin{array}{l}\text { 212751_at, 225179_at, 201899_s_at, 202334_s_at, 211763_s_at, 201371_s_at, 201370_s_at, } \\
\text { 202823_at, 202824_s_at, 226005_at, 213128_s_at, 229355_at, 200667_at, 223651_x_at, } \\
\text { 203531_at, 1552617_a_at, 214281_s_at, 235222_x_at, 202717_s_at, 209455_at, 201343_at, } \\
\text { 201345_s_at, 225783_at, }\end{array}$ \\
\hline \multicolumn{3}{|l|}{ Bipolar } \\
\hline $\begin{array}{l}\text { hsa04120:Ubiquitin mediated } \\
\text { proteolysis }\end{array}$ & 0.013783 & $\begin{array}{l}\text { 225521_at, 224471_s_at, 204022_at, 204598_at, 235222_x_at, 222480_at, 244633_at, } \\
\text { 243624_at, }\end{array}$ \\
\hline \multicolumn{3}{|l|}{ Major depression } \\
\hline $\begin{array}{l}\text { hsa04120:Ubiquitin mediated } \\
\text { proteolysis }\end{array}$ & 0.032073 & $\begin{array}{l}\text { 211763_s_at, 202334_s_at, 236233_at, 201370_s_at, 213117_at, 202214_s_at, 214281_s_at, } \\
\text { 235222_x_at, 202892_at, 224747_at, }\end{array}$ \\
\hline
\end{tabular}

Abbreviation: KEGG, Kyoto Encyclopedia of Genes and Genomes. 
Table 4c Gene names for KEGG pathway-identified AFFY_IDs

\begin{tabular}{|c|c|c|}
\hline 208898_at & ATP6V1D & ATPase, $\mathrm{H}+$ transporting, lysosomal $34 \mathrm{kDa}, \mathrm{V} 1$ subunit $\mathrm{D}$ \\
\hline 201097_s_at & ARF4 & ADP-ribosylation factor 4 \\
\hline 222646_s_at & ERO1L & ERO1-like (S. cerevisiae) \\
\hline 204732_s_at & ARFD1 & ADP-ribosylation factor domain protein $1,64 \mathrm{kDa}$ \\
\hline 226463_at & ATP6V1C1 & ATPase, $\mathrm{H}+$ transporting, lysosomal $42 \mathrm{kDa}$, V1 subunit $\mathrm{C}$, isoform 1 \\
\hline 202872_at & ATP6V1C1 & ATPase, $\mathrm{H}+$ transporting, lysosomal $42 \mathrm{kDa}$, V1 subunit $\mathrm{C}$, isoform 1 \\
\hline 238765_at & LOC283431 & hypothetical protein LOC283431 \\
\hline 235980_at & KCNMB3 & potassium large conductance calcium-activated channel, subfamily M beta member 3 \\
\hline 204507_s_at & PPP3R1 & protein phosphatase 3 (formerly $2 \mathrm{~B}$ ), regulatory subunit $\mathrm{B}, 19 \mathrm{kDa}$, alpha isoform (calcineurin $\mathrm{B}$, type I) \\
\hline 229606_at & PPP3CA & protein phosphatase 3 (formerly 2B), catalytic subunit, alpha isoform (calcineurin A alpha) \\
\hline 1567458_s_at & RAC1 & ras-related C3 botulinum toxin substrate 1 (rho family, small GTP binding protein Rac1) \\
\hline 212688_at & PIK3CB & phosphoinositide-3-kinase, catalytic, beta polypeptide \\
\hline 32541_at & PPP3CC & protein phosphatase 3 (formerly 2B), catalytic subunit, gamma isoform (calcineurin A gamma) \\
\hline 226183_at & GSK3B & glycogen synthase kinase 3 beta \\
\hline 228388_at & NFKBIB & nuclear factor of kappa light polypeptide gene enhancer in B-cells inhibitor, beta \\
\hline 242323_at & & $\begin{array}{l}\text { Homo sapiens transcribed sequence with weak similarity to protein ref:NP_060312.1 (H.sapiens) } \\
\text { hypothetical protein FLJ20489 [Homo sapiens] }\end{array}$ \\
\hline 202670_at & MAP2K1 & mitogen-activated protein kinase kinase 1 \\
\hline 214230_at & & cell division cycle 42 (GTP binding protein, $25 \mathrm{kDa}$ ) \\
\hline 201233_at & PSMD13 & proteasome (prosome, macropain) 26S subunit, non-ATPase, 13 \\
\hline 237240_at & & Homo sapiens cDNA FLJ42752 fis, clone BRAWH3000604 \\
\hline 200876_s_at & PSMB1 & proteasome (prosome, macropain) subunit, beta type, 1 \\
\hline 200830_at & PSMD2 & proteasome (prosome, macropain) 26S subunit, non-ATPase, 2 \\
\hline 201316_at & PSMA2 & proteasome (prosome, macropain) subunit, alpha type, 2 \\
\hline 203157_s_at & GLS & glutaminase \\
\hline 200843_s_at & EPRS & glutamyl-prolyl-tRNA synthetase \\
\hline 229333_at & & Homo sapiens transcribed sequence with weak similarity to protein sp:P39193 (H.sapiens) ALU6_HU- \\
\hline & & MAN Alu subfamily SP sequence contamination warning entry \\
\hline 202922_at & GCLC & glutamate-cysteine ligase, catalytic subunit \\
\hline 209434_s_at & PPAT & phosphoribosyl pyrophosphate amidotransferase \\
\hline 213849_s_at & PPP2R2B & protein phosphatase 2 (formerly $2 A$ ), regulatory subunit $B$ (PR 52), beta isoform \\
\hline 201381_x_at & SIP & Siah-interacting protein \\
\hline 235502_at & PPP2CA & protein phosphatase 2 (formerly $2 \mathrm{~A}$ ), catalytic subunit, alpha isoform \\
\hline 212072_s_at & & casein kinase 2 , alpha 1 polypeptide \\
\hline 201614_s_at & RUVBL1 & RuvB-like 1 (E. coli) \\
\hline 226666_at & DAAM1 & dishevelled associated activator of morphogenesis 1 \\
\hline 219683_at & FZD3 & frizzled homolog 3 (Drosophila) \\
\hline 226183_at & GSK3B & glycogen synthase kinase 3 beta \\
\hline 209455_at & FBXW1B & F-box and WD-40 domain protein 1B \\
\hline 235780_at & & protein kinase, cAMP-dependent, catalytic, beta \\
\hline 202762_at & ROCK2 & Rho-associated, coiled-coil containing protein kinase 2 \\
\hline 209281_s_at & ATP2B1 & ATPase, $\mathrm{Ca}++$ transporting, plasma membrane 1 \\
\hline 206355_at, & GNAL & guanine nucleotide binding protein (G protein), alpha activating activity polypeptide, olfactory type \\
\hline 236013_at, & CACNA1E & calcium channel, voltage-dependent, alpha $1 \mathrm{E}$ subunit \\
\hline 238546_at, & SLC8A1 & solute carrier family 8 (sodium/calcium exchanger), member 1 \\
\hline 241752_at, & SLC8A1 & solute carrier family 8 (sodium/calcium exchanger), member 1 \\
\hline 235049_at, & & adenylate cyclase 1 (brain) \\
\hline 207522_s_at, & ATP2A3 & ATPase, $\mathrm{Ca}++$ transporting, ubiquitous \\
\hline 218341_at, & FLJ20972 & hypothetical protein FLJ20972 \\
\hline 202993_at, & ILVBL & ilvB (bacterial acetolactate synthase)-like \\
\hline 225285_at, & BCAT1 & branched chain aminotransferase 1 , cytosolic \\
\hline 218809_at, & PANK2 & pantothenate kinase 2 (Hallervorden-Spatz syndrome) \\
\hline 218433_at, & PANK3 & pantothenate kinase 3 \\
\hline 205630_at, & $\mathrm{CRH}$ & corticotropin releasing hormone \\
\hline 203710_at, & ITPR 1 & inositol 1,4,5-triphosphate receptor, type 1 \\
\hline 214352_s_at, & KRAS2 & v-Ki-ras2 Kirsten rat sarcoma 2 viral oncogene homolog \\
\hline 204009_s_at, & KRAS2 & v-Ki-ras2 Kirsten rat sarcoma 2 viral oncogene homolog \\
\hline 227692_at, & GNAI1 & guanine nucleotide binding protein (G protein), alpha inhibiting activity polypeptide 1 \\
\hline 222036_s_at, & & MCM4 minichromosome maintenance deficient 4 (S. cerevisiae) \\
\hline 204853_at, & ORC2L & origin recognition complex, subunit 2-like (yeast) \\
\hline 214848_at, & YWHAZ & Homo sapiens similar to 40 S ribosomal protein S26 (LOC375677), mRNA \\
\hline 209903_s_at, & ATR & ataxia telangiectasia and Rad3 related \\
\hline
\end{tabular}




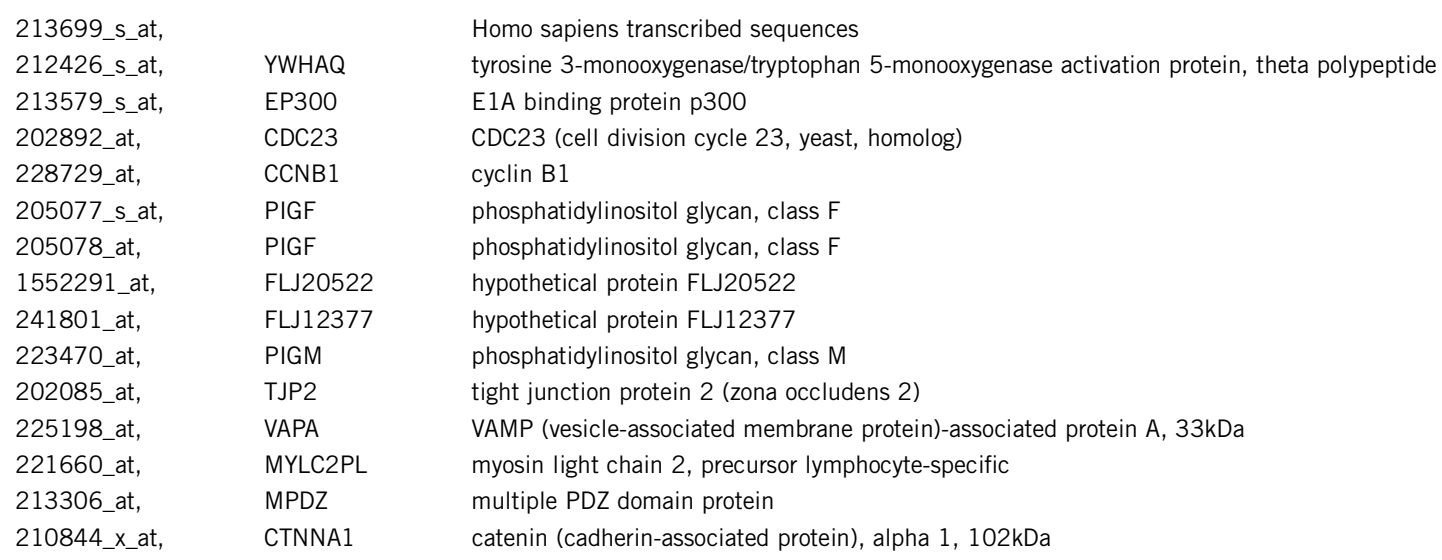

Abbreviation: KEGG, Kyoto Encyclopedia of Genes and Genomes.

identified SZ-associated and unique transcripts and functional pathways are now shown to be unique to $\mathrm{SZ}$ and not to either BP or MD.

Screening the whole human genome of MDNp neurons supports a neuron-specific deficiency of gene expression in three psychiatric disorders. Overall, there are significant differences among psychiatric disorders, with SZ showing the largest number of transcriptional changes. Thus, the molecular dysregulation of genes specific to each disease state related to thalamocortical circuitry may reveal underlying neuropathological differences in each disorder.

Potential drug effects pose a major interpretive problem for this study. Some differences between the patient groups and NCs could reflect the fact that the majority of the subjects in the patient groups had significant histories of exposure to medications that alter neuronal function. As the histories of drug exposures differed dramatically across patient groups, it is not possible to determine whether betweenpatient group differences reflect variation in the pathophysiology of their mental illness as opposed to particular medication exposure. To answer these questions would require post-mortem samples from sufficient numbers of unmedicated subjects in each group, or from patients with different disorders who had identical drug exposures. Thus, these questions can presently be approached only through animal studies.

\section{ACKNOWLEDGEMENTS}

We are grateful for the full support of the Microarray Shared Resources Facilities at Mount Sinai School of Medicine. This work was supported by The Stanley Medical Research Institute grant (EK). A special thanks to William Byne, MD, PhD for assistance in anatomical oversight of the thalamic parcellation, template production and figure preparation, to Ghe Vong for assistance in preparation of Figure 1 and to Kalindi Bakshi, $\mathrm{PhD}$ for help in paper preparation.

1 Jones, E. G. The thalamic matrix and thalamocortical synchrony. Trends Neurosci. 24, 595-601 (2001).

2 Johnstone, T., van Reekum, C. M., Urry, H. L., Kalin, N. H. \& Davidson, R. J. Failure to regulate: counterproductive recruitment of top-down prefrontal-subcortical circuitry in major depression. J. Neurosci. 27, 8877-8884 (2007).

3 Bleier, R. Retrograde transsynaptic cellular degeneration in mammillary and ventral tegmental nuclei following limbic decortication in rabbits of various ages. Brain Res. 15, 365-393 (1969).

4 Lehrer, D. S., Christian, B. T., Mantil, J., Murray, A. C., Buchsbaum, B. R., Oakes, T. R. et al. Thalamic and prefrontal FDG uptake in never medicated patients with schizophrenia. Am. J. Psychiatry 162, 931-938 (2005).
5 Selemon, L. D., Rajkowska, G. \& Goldman-Rakic, P. S. Abnormally high neuronal density in the schizophrenic cortex. A morphometric analysis of prefrontal area 9 and occipital area 17. Arch. Gen. Psychiatry 52, 805-818. discussion 819-20 (1995).

6 Byne, W., Buchsbaum, M. S., Mattiace, L. A., Hazlett, E. A., Kemether, E., Elhakem, S. L. et al. Postmortem assessment of thalamic nuclear volumes in subjects with schizophrenia. Am. J. Psychiatry 159, 59-65 (2002).

7 Danos, P., Baumann, B., Kramer, A., Bernstein, H. G., Stauch, R., Krell, D. et al. Volumes of association thalamic nuclei in schizophrenia: a postmortem study. Schizophr. Res. 60, 141-155 (2003).

8 Hazlett, E. A., Buchsbaum, M. S., Kemether, E., Bloom, R., Platholi, J., Brickman, A. M. et al. Abnormal glucose metabolism in the mediodorsal nucleus of the thalamus in schizophrenia. Am. J. Psychiatry 161, 305-314 (2004).

9 Popken, G. J., Bunney, Jr. W. E. Potkin, S. G. \& Jones, E. G. Subnucleus-specific loss of neurons in medial thalamus of schizophrenics. Proc. Natl Acad. Sci. USA 97, 9276-9280 (2000).

10 Cullen, T. J., Walker, M. A., Parkinson, N., Craven, R., Crow, T. J., Esiri, M. M. et al. A postmortem study of the mediodorsal nucleus of the thalamus in schizophrenia. Schizophr. Res. 60, 157-166 (2003).

11 Dorph-Petersen, K. A., Pierri, J. N., Sun, Z., Sampson, A. R. \& Lewis, D. A. Stereological analysis of the mediodorsal thalamic nucleus in schizophrenia: volume, neuron number, and cell types. J. Comp. Neurol. 472, 449-462 (2004).

12 Young, K. A., Holcomb, L. A., Yazdani, U., Hicks, P. B. \& German, D. C. Elevated neuron number in the limbic thalamus in major depression. Am. J. Psychiatry 161, 1270-1277 (2004).

13 Buchsbaum, M. S. \& Hazlett, E. A. Positron emission tomography studies of abnormal glucose metabolism in schizophrenia. Schizophr. Bull. 24, 343-364 (1998).

14 Hazlett, E. A., Buchsbaum, M. S., Zhang, J., Newmark, R. E., Glanton, C. F. \& Zelmanova, Y. Frontal-striatal-thalamic mediodorsal nucleus dysfunction in schizophrenia-spectrum patients during sensorimotor gating. Neuroimage 42, 1164-1177 (2008).

15 Kemether, E. M., Buchsbaum, M. S., Byne, W., Hazlett, E. A., Haznedar, M., Brickman, A. M. et al. Magnetic resonance imaging of mediodorsal, pulvinar, and centromedian nuclei of the thalamus in patients with schizophrenia. Arch. Gen. Psychiatry 60, 983-991 (2003).

16 Mitelman, S. A., Byne, W., Kemether, E. M., Hazlett, E. A. \& Buchsbaum, M. S. Metabolic disconnection between the mediodorsal nucleus of the thalamus and cortical Brodmann's areas of the left hemisphere in schizophrenia. Am. J. Psychiatry 162, 1733-1735 (2005).

17 Olney, J. W. \& Farber, N. B. Glutamate receptor dysfunction and schizophrenia. Arch. Gen. Psychiatry 52, 998-1007 (1995).

18 Goff, D. C. \& Coyle, J. T. The emerging role of glutamate in the pathophysiology and treatment of schizophrenia. Am. J. Psychiatry 158, 1367-1377 (2001).

19 Lewis, D. A. \& Moghaddam, B. Cognitive dysfunction in schizophrenia: convergence of gamma-aminobutyric acid and glutamate alterations. Arch. Neurol. 63, 1372-1376 (2006).

20 Byne, W., Hazlett, E. A., Buchsbaum, M. S. \& Kemether, E. The thalamus and schizophrenia: current status of research. Acta Neuropathol. 117, 347-368 (2008).

21 Torrey, E. F., Webster, M., Knable, M., Johnston, N. \& Yolken, R. H. The stanley foundation brain collection and neuropathology consortium. Schizophr. Res. 44, 151-155 (2000).

22 Ray, J. P. \& Price, J. L. The organization of projections from the mediodorsal nucleus of the thalamus to orbital and medial prefrontal cortex in macaque monkeys. J. Comp. Neurol. 337, 1-31 (1993).

23 Bleier, R., Byne, W. \& Siggelkow, I. Cytoarchitectonic sexual dimorphisms of the medial preoptic and anterior hypothalamic areas in guinea pig, rat, hamster, and mouse. J.Comp. Neurol. 212, 118-130 (1982). 
24 Mufson, E. J., Counts, S. E., Che, S. \& Ginsberg, S. D. Neuronal gene expression profiling: uncovering the molecular biology of neurodegenerative disease. Prog. Brain Res. 158, 197-222 (2006).

25 Perez-Manso, M., Barroso-Chinea, P., Aymerich, M. S. \& Lanciego, J. L. 'Functional' neuroanatomical tract tracing: analysis of changes in gene expression of brain circuits of interest. Brain Res. 1072, 91-98 (2006).

26 Murray, K. D., Choudary, P. V. \& Jones, E. G. Nucleus- and cell-specific gene expression in monkey thalamus. Proc. Natl Acad. Sci. USA 104, 1989-1994 (2007).

27 Irizarry, R. A., Bolstad, B. M., Collin, F., Cope, L. M., Hobbs, B. \& Speed, T. P. Summaries of Affymetrix GeneChip probe level data. Nucleic Acids Res. 31, e15 (2003).

28 Vawter, M. P., Tomita, H., Meng, F., Bolstad, B., Li, J., Evans, S. et al. Mitochondrialrelated gene expression changes are sensitive to agonal-pH state: implications for brain disorders. Mol. Psychiatry 11: 615 663-679 (2006).

29 Tomita, H., Vawter, M. P., Walsh, D. M., Evans, S. J., Choudary, P. V., Li, J. et al. Effect of agonal and postmortem factors on gene expression profile: quality control in microarray analyses of postmortem human brain. Biol. Psychiatry 55, 346-352 (2004).

30 Huang, da W., Sherman, B. T. \& Lempicki, R. A. Systematic and integrative analysis of large gene lists using DAVID bioinformatics resources. Nat. Protoc. 4, 44-57 (2009).

31 Hosack, D. A., Dennis, Jr G., Sherman, B. T., Lane, H. C. \& Lempicki, R. A. Identifying biological themes within lists of genes with EASE. Genome Biol. 4, R70 (2003).

32 Dennis, Jr G, Sherman, B. T., Hosack, D. A., Yang, J., Gao, W., Lane, H. C. et al. DAVID: Database for Annotation, Visualization, and Integrated Discovery. Genome Biol. 4, P3 (2003).

33 Steffek, A. E., McCullumsmith, R. E., Haroutunian, V. \& Meador-Woodruff, J. H. Cortical expression of glial fibrillary acidic protein and glutamine synthetase is decreased in schizophrenia. Schizophr. Res. 103, 71-82 (2008).

34 Altar, C. A., Hunt, R. A., Jurata, L. W., Webster, M. J., Derby, E., Gallagher, P. et al. Insulin, IGF-1, and muscarinic agonists modulate schizophrenia-associated genes in human neuroblastoma cells. Biol. Psychiatry 64, 1077-1087 (2008).

35 Altar, C. A., Jurata, L. W., Charles, V., Lemire, A., Liu, P., Bukhman, Y. et al. Deficient hippocampal neuron expression of proteasome, ubiquitin, and mitochondrial genes in multiple schizophrenia cohorts. Biol. Psychiatry 58, 85-96 (2005).

36 Zhao, Z., Ksiezak-Reding, H., Riggio, S., Haroutunian, V. \& Pasinetti, G. M. Insulin receptor deficits in schizophrenia and in cellular and animal models of insulin receptor dysfunction. Schizophr. Res. 84, 1-14 (2006).

37 Emamian, E. S., Hall, D., Birnbaum, M. J., Karayiorgou, M. \& Gogos, J. A. Convergent evidence for impaired AKT1-GSK3beta signaling in schizophrenia. Nat. Genet. 36, 131-137 (2004).

38 Schieke, S. M., Phillips, D., McCoy, Jr J. P, Aponte, A. M., Shen, R. F., Balaban, R. S. et al. The mammalian target of rapamycin (mTOR) pathway regulates mitochondrial oxygen consumption and oxidative capacity. J. Biol. Chem. 281, 27643-27652 (2006).

39 Martins-de-Souza, D., Gattaz, W. F., Schmitt, A., Rewerts, C., Marangoni, S., Novello, J. C. et al. Alterations in oligodendrocyte proteins, calcium homeostasis and new potential markers in schizophrenia anterior temporal lobe are revealed by shotgun proteome analysis. J. Neural Transm. 116, 275-289 (2009).

40 Dai, Y. S., Xu, J. \& Molkentin, J. D. The DnaJ-related factor Mrj interacts with nuclear factor of activated T cells $\mathrm{c} 3$ and mediates transcriptional repression through class II histone deacetylase recruitment. Mol. Cell. Biol. 25, 9936-9948 (2005).

41 Parrilla-Castellar, E. R., Arlander, S. J. \& Karnitz, L. Dial 9-1-1 for DNA damage: the Rad9-Hus1-Rad1 (9-1-1) clamp complex. DNA Repair. (Amst) 3, 1009-1014 (2004).

42 Occhi, G., Rampazzo, A., Beffagna, G. \& Antonio Danieli, G. Identification and characterization of heart-specific splicing of human neurexin 3 mRNA (NRXN3). Biochem. Biophys. Res. Commun. 298, 151-155 (2002).
43 Dean, C. \& Dresbach, T. Neuroligins and neurexins: linking cell adhesion, synapse formation and cognitive function. Trends Neurosci. 29, 21-29 (2006).

44 Graf, E. R., Kang, Y., Hauner, A. M. \& Craig, A. M. Structure function and splice site analysis of the synaptogenic activity of the neurexin-1 beta LNS domain. J. Neurosci. 26, 4256-4265 (2006).

45 Graf, E. R., Zhang, X., Jin, S. X., Linhoff, M. W. \& Craig, A. M. Neurexins induce differentiation of GABA and glutamate postsynaptic specializations via neuroligins. Cell 119, 1013-1026 (2004).

46 Missler, M., Fernandez-Chacon, R. \& Sudhof, T. C. The making of neurexins. J. Neurochem. 71, 1339-1347 (1998).

47 Ushkaryov, Y. A., Petrenko, A. G., Geppert, M. \& Sudhof, T. C. Neurexins: synaptic cell surface proteins related to the alpha-latrotoxin receptor and laminin. Science 257, 50-56 (1992).

48 Nam, C. I. \& Chen, L. Postsynaptic assembly induced by neurexin-neuroligin interaction and neurotransmitter. Proc. Natl Acad. Sci. USA 102, 6137-6142 (2005).

49 Hishimoto, A., Liu, Q. R., Drgon, T., Pletnikova, O., Walther, D., Zhu, X. G. et al. Neurexin 3 polymorphisms are associated with alcohol dependence and altered expression of specific isoforms. Hum. Mol. Genet. 16, 2880-2891 (2007).

50 Bierut, L. J., Madden, P. A., Breslau, N., Johnson, E. O., Hatsukami, D., Pomerleau, O. F. et al. Novel genes identified in a high-density genome wide association study for nicotine dependence. Hum. Mol. Genet. 16, 24-35 (2007).

51 Lachman, H. M., Fann, C. S., Bartzis, M., Evgrafov, O. V., Rosenthal, R. N., Nunes, E. V. et al. Genomewide suggestive linkage of opioid dependence to chromosome 14q. Hum. Mol. Genet. 16, 1327-1334 (2007).

52 Mirnics, K., Levitt, P. \& Lewis, D. A. Critical appraisal of DNA microarrays in psychiatric genomics. Biol. Psychiatry 60, 163-176 (2006).

53 Mirnics, K., Middleton, F. A., Marquez, A., Lewis, D. A. \& Levitt, P. Molecular characterization of schizophrenia viewed by microarray analysis of gene expression in prefrontal cortex. Neuron 28, 53-67 (2000).

54 Iwamoto, K., Bundo, M. \& Kato, T. Altered expression of mitochondria-related genes in postmortem brains of patients with bipolar disorder or schizophrenia, as revealed by large-scale DNA microarray analysis. Hum. Mol. Genet. 14, 241-253 (2005).

55 Prabakaran, S., Swatton, J. E., Ryan, M. M., Huffaker, S. J., Huang, J. T., Griffin, J. L. et al. Mitochondrial dysfunction in schizophrenia: evidence for compromised brain metabolism and oxidative stress. Mol. Psychiatry 9, 684-697. 643 (2004).

56 Li, J. Z., Vawter, M. P., Walsh, D. M., Tomita, H., Evans, S. J., Choudary, P. V. et al. Systematic changes in gene expression in postmortem human brains associated with tissue $\mathrm{pH}$ and terminal medical conditions. Hum. Mol. Genet. 13, 609-616 (2004).

57 Eastwood, S. L. \& Harrison, P. J. Decreased mRNA expression of netrin-G1 and netrinG2 in the temporal lobe in schizophrenia and bipolar disorder. Neuropsychopharmacology 33, 933-945 (2008).

58 Risch, N. Genetic linkage and complex diseases, with special reference to psychiatric disorders. Genet. Epidemiol. 7, 3-16. discussion 17-45 (1990).

59 Chumakov, L., Blumenfeld, M., Guerassimenko, O., Cavarec, L., Palicio, M. \& Abderrahim, H. Genetic and physiological data implicating the new human gene G72 and the gene for D-amino acid oxidase in schizophrenia. Proc. Natl Acad. Sci. USA 99, 13675-13680 (2002).

60 O'Donovan, M. C., Craddock, N., Norton, N., Williams, H., Peirce, T., Moskvina, V. et al. Identification of loci associated with schizophrenia by genome-wide association and follow-up. Nat. Genet. 40, 1053-1055 (2008).

61 Brazma, A. \& Vilo, J. Gene expression data analysis. FEBS Lett. 480, 17-24 (2000).

62 Sobell, J. L., Mikesell, M. J. \& McMurray, C. T. Genetics and etiopathophysiology of schizophrenia. Mayo Clin. Proc. 77, 1068-1082 (2002).

Supplementary Information accompanies the paper on Journal of Human Genetics website (http://www.nature.com/jhg) 